\title{
DESDOBRAMENTO DAS CORRELAÇÕES DAS NOTAS DO EXAME NACIONAL DO ENSINO MÉDIO VIA ANÁLISE DE TRILHA NA REGIÃO DO CAPARAÓ ${ }^{1}$
}

\author{
Marcelo Henrique de Souza2 \\ André Oliveira Souza ${ }^{3}$
}

\begin{abstract}
RESUMO
O Exame Nacional de Ensino Médio (ENEM) contribui para que o Governo Federal possa definir políticas públicas educacionais, como a certificação para aquele (as) que não concluíram o ensino médio. O trabalho teve como objetivo a construção do diagrama de trilha indicando as relações causa efeitos entre as áreas de conhecimento avaliadas pelo ENEM2014 na região do Caparaó, tendo a variável básica definida a matemática. Na metodologia foi utilizado o coeficiente de trilha para a visualização dos efeitos diretos e indiretos na matemática via outras áreas de conhecimento auxiliando a visualização de causa e efeito; obteve-se informações no site do INEP nos microdados do ENEM do referido ano, obtendo os vetores de média por área avaliada das escolas estaduais do Caparaó via códigos das escolas; as informações foram trabalhadas no software Genes. Em um quantitativo de 1999 estudantes que se inscreveram, 221 estão com notas NA (Not Avalilable) em, pelo menos, uma das áreas avaliadas que aqui neste estudo não foram considerados. $\mathrm{O}$ efeito residual do modelo foi de 0,460 e o $R^{2}=0,790$ e observou-se que as variáveis Ciência da Natureza $(\mathrm{CN})$ e Ciências Humanas $(\mathrm{CH})$ mostraram efeitos diretos e positivos 0,421 e 0,509 respectivamente em matemática e Redação (RED), -0,074 e Códigos e Linguagens (LC) 0,045 com efeitos diretos aproximadamente nulos. Observou-se que os efeitos indiretos para todas as outras áreas via redação foram negativos (nulo).
\end{abstract}

Palavras Chave: Diagrama de trilha. Variável básica. Microdados do ENEM.

\section{INTRODUÇÃO}

Esse trabalho realizou-se na região do Caparaó abrangendo sete municípios do Espírito Santo e quatro em Minas Gerais e suas respectivas escolas estaduais que participaram do ENEM em 2014 via códigos das mesmas.

\footnotetext{
${ }^{1}$ Como citar este artigo: SOUZA, Marcelo Henrique de; SOUZA, André Oliveira. Desdobramentos das correlações das notas do Exame Nacional do Ensino Médio via análise de trilha na região do Caparaó. ForScience: revista científica do IFMG, Formiga, v.5, n.3, e00265, 2017.

${ }^{2}$ Mestre em Meio Ambiente e Sustentabilidade pela Funec/Unec e professor do Instituto Federal do Espírito Santo - Campus Alegre. E-mail: marcelosouza.rec @ hotmail.com. Currículo Lattes: http//lattes.cnpq. br/ 23573 85391220121.

${ }^{3}$ Doutorando em Produção Vegetal pela Universidade Estadual do Norte Fluminense Darcy Ribeiro. Professor do Instituto Federal do Espírito Santo - IFES - Campus de Alegre. E-mail: andreolisouza@gmail.com. Currículo Lattes: http://lattes.cnpq.br/5802669165872867.
} 
Desde 1998 o Enem tem como premissas avaliar os estudantes de escolas públicas e particulares do Ensino Médio. Os resultados servem de base para o desempenho pessoal utilizados pelo governo para definir políticas públicas educacionais.

O programa é composto por duas etapas: uma redação com o tema proposto pela banca e uma etapa de múltipla escolha envolvendo as áreas de conhecimento: ciências humanas, da natureza, códigos e linguagens com testes objetivos. O participante do Enem interessado em obter o certificado de conclusão do Ensino Médio ou a declaração parcial de proficiência deverá atender a vários requisitos.

O trabalho teve como objetivo a construção do diagrama de trilha mostrando as interrelações entre as áreas de conhecimento, tendo a variável básica definida a matemática.

\section{CONSIDERAÇÕES GERAIS}

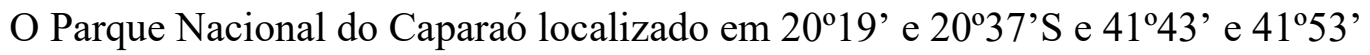
(INSTITUTO CHICO MENDES DE CONSERVAÇÃO DA BIODIVERSIDADE, [20--?]). Ele abrange os municípios de Iúna, Ibitirama, Irupi, Dores do Rio Preto, Divino de São Lourenço, Guaçuí e Alegre do lado capixaba e Alto Caparaó, Caparaó, Alto Jequitibá e Espera Feliz do lado mineiro (INSTITUTO CHICO MENDES DE CONSERVAÇÃO DA BIODIVERSIDADE, [20--?]).

O ENEM ocorre no Brasil desde 1988, servindo de base para o ingresso de estudantes em Universidades públicas e privadas no país e formas de mensurar o desempenho dos estudantes do Ensino Médio (BRASIL, 2005). Esse modelo de avaliação fica atrás somente do gaokao realizado na China em termos de ingressos no ensino superior. O exame não é obrigatório, porém, a cada ano tem atraído muitos estudantes (BRASIL, 2015).

De acordo com o INEP:

O participante do ENEM interessado em obter o certificado de conclusão do Ensino Médio ou a declaração parcial de proficiência deverá atender aos seguintes requisitos: indicar a pretensão de utilizar os resultados de desempenho no exame para fins de certificação de conclusão do Ensino Médio, no ato da inscrição, bem como a Instituição Certificadora; possuir no mínimo 18 anos completos na data da primeira prova de cada edição do exame; atingir o mínimo de 450 pontos em cada uma das áreas de conhecimento do exame; atingir o mínimo de 500 pontos na redação (BRASIL, 2005). 
SOUZA, M. H. de; SOUZA, A. O. Desdobramento das correlações das notas do Exame Nacional do Ensino Médio via análise de trilha na região do Caparaó

Para a confecção do diagrama de trilha teve como embasamento vários autores. Segundo Li (1956), o coeficiente de trilha é uma ferramenta que analisa um sistema de múltiplas variáveis, relacionadas de modo linear e inclui todos os fatores básicos e suas variáveis resultantes. O estudo do coeficiente de trilha pode auxiliar a visualização do efeito direto que um caráter causa no outro e os efeitos indiretos dos outros caracteres relacionados (PAIVA; ROSSETTI; GONÇALVES, 1982).

Esse tipo de estudo vem amparando a formulação de procedimentos apropriados para seleção de um conjunto de fatores hereditários em diversas culturas agrícolas no país (CARVALHO et al., 1999; SANTOS; CARVALHO; SANTOS, 2000; COIMBRA et al., 2005; MARCHEZAN et al., 2005). Que no trabalho, substituiu-se as diversas culturas agrícolas pelas médias do ENEM. Segundo Cruz e Carneiro (2003), a análise de trilha permite a obtenção de informações a respeito dos efeitos diretos e indiretos de um grupo de caracteres, em relação a um determinado caráter considerado de maior importância.

Assim, é importante identificar entre as características de alta correlação com a variável básica, as de maior efeito direto no sentido favorável à seleção, de tal forma que a resposta correlacionada por meio da seleção indireta seja eficaz (SEVERINO et al., 2002).

\section{METODOLOGIA}

Utilizou-se o coeficiente de trilha para a visualização dos efeitos diretos e indiretos na matemática via outras áreas de conhecimento auxiliando a visualização de causa e efeito; obteve-se informações no site do INEP nos microdados do ENEM do referido ano, obtendo os vetores de média por área avaliada das escolas estaduais do Caparaó via códigos das escolas; as informações foram trabalhadas no software Genes.

\section{RESULTADOS E DISCUSSÃO}

Identificou-se 34 instituições, totalizando 1999 estudantes que fizeram o exame em 2014, destes 221 estão com notas NA (Not Avalilable) em, pelo menos, uma das áreas avaliadas. Sendo assim para o cálculo percentual de aluno que conseguiriam obter o certificado de ensino médio de acordo com as normas do edital 2014 foi considerado 1779 alunos que totalizou $26,46 \%$ aptos a tal certificação. Destes 1779 alunos apenas um declarou 
ter deficit de atenção, nenhum declarou dislexia, dois declararam ter baixa visão e nenhum declarou altismo. As médias para o Caparaó capixaba e Caparaó Mineiro foram obtidas com a exclusão NA (Not Avalilable) e estão plotadas na Figura 1 e que não diferiram pelo teste qui quadrado pvalor $=0,9699$.



Figura 1 - Médias por região e áreas avaliadas no ENEM2014 Fonte: Do autor (2017).

Com objetivo de estudar a relação causa efeito foi obtida a matriz de correlação entre as notas médias de cada área e com posterior desdobramento da correlação pela análise de trilha, sendo matemática definida como variável primária. As correções de Pearson entre os vetores de médias estão na Tabela 1 e que pode observar que as correlações entre todas as variáveis foram acima de 0,700 e todas foram significativas a 5\% de probabilidade. Acima da diagonal principal estão as correlações e abaixo os pvalores associados a cada correlação. E na tabela 2 estão os coeficientes do desdobramento da correlação indicando os efeitos direto e indiretamente sobre a variável básica definida obtidos via análise de trilha, que resultou na construção do diagrama de trilha. 
SOUZA, M. H. de; SOUZA, A. O. Desdobramento das correlações das notas do Exame Nacional do Ensino Médio via análise de trilha na região do Caparaó

Tabela 1 - Correlação entre os vetores de médias das notas das áreas avaliadas e os respectivos pvalores associados a cada correlação

\begin{tabular}{ccccc}
\hline Mat & CN & CH & LC & Red \\
\hline Mat. 1.000000 & 0.859283 & 0.869000 & 0.809136 & 0.700995 \\
CN 0.000000 & 1.000000 & 0.899349 & 0.875042 & 0.794419 \\
CH 0.000000 & 0.000000 & 1.000000 & 0.894956 & 0.794796 \\
LC 0.000000 & 0.000000 & 0.000000 & 1.000000 & 0.806828 \\
Red. 0.000000 & 0.000000 & 0.000000 & 0.000000 & 1.000000 \\
\hline
\end{tabular}

Fonte: Do autor (2017).

Tabela 2 - Coeficientes dos desdobramentos das correlações via análise de trilha

\begin{tabular}{lcccc}
\hline & $\mathrm{CN}$ & $\mathrm{CH}$ & $\mathrm{LC}$ & $\mathrm{Red}$ \\
\hline Efeito direto sobre matemática & 0,421 & 0,509 & 0,045 & $-0,075$ \\
Efeito indireto via CN & - & 0,379 & 0,368 & 0,334 \\
Efeito indireto via CH & 0,458 & - & 0,455 & 0,405 \\
Efeito indireto via LC & 0,039 & 0,040 & - & 0,036 \\
Efeito indireto via RED & $-0,059$ & $-0,059$ & $-0,060$ & - \\
Total & 0,860 & 0,869 & 0,808 & 0,700 \\
$\mathrm{R}^{2}$ & 0,790 & & & \\
Efeito Residual & 0,460 & & & \\
Det(X'X) & & & & \\
\hline
\end{tabular}

Fonte: Do autor (2017).

Os efeitos diretos das variáveis $(\mathrm{CN}, \mathrm{CH})$ foram positivos 0,421 e 0,509 respectivamente e RED $(-0,075)$ e LC $(0,045)$ que pode ser considerado aproximadamente nulo. Observa que os efeitos indiretos via redação foi negativo (aproximadamente nulo) para todas as áreas. $\mathrm{O} \mathrm{R}^{2}=0,790$ e o Efeito Residual 0,460 indicam que as outras áreas explicam as notas da matemática e que está representado no diagrama de trilha na figura 1. 
SOUZA, M. H. de; SOUZA, A. O. Desdobramento das correlações das notas do Exame Nacional do Ensino Médio via análise de trilha na região do Caparaó

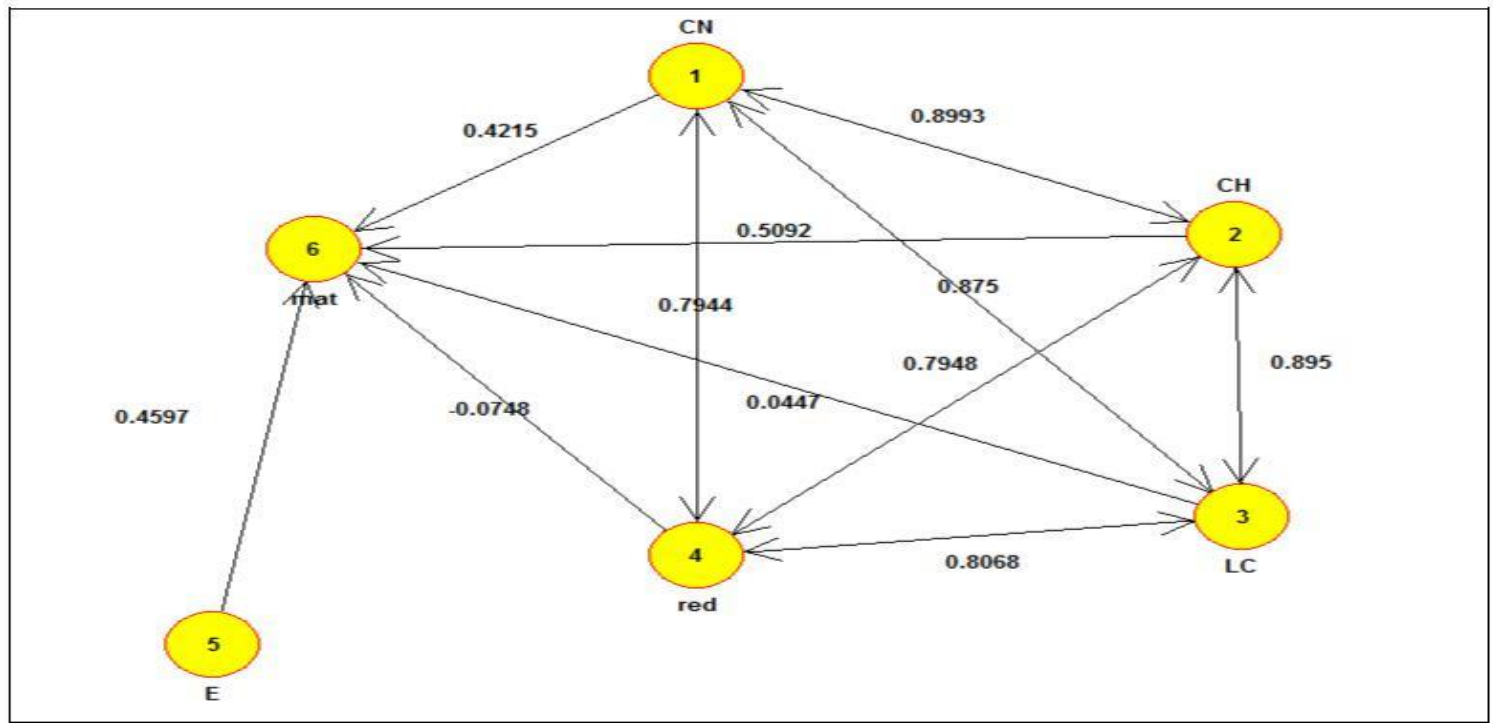

Figura 2 - Diagrama de trilha respectivos coeficientes dos efeitos diretos e indiretos Fonte: Do autor (2017).

\title{
5 CONCLUSÃO
}

A análise de trilha mostrou-se uma ferramenta com potencial para identificar os efeitos diretos e indiretos das outras áreas sobre o rendimento de matemática, pois, o modelo teve efeito residual baixo. $\mathrm{O}$ desdobramento das correlações entre as áreas avaliadas possibilitou observar quais foram as áreas que tiveram efeitos diretos e indiretos sobre a matemática. As áreas de $\mathrm{CN}$ e $\mathrm{CH}$ tiveram efeitos diretos maiores sobre a matemática e a área de RED e LC tiveram efeitos quase nulo sobre a matemática. Os maiores efeitos indiretos sobre a matemática foram das áreas de CN, LC e RED via CH.

Contudo, pretende-se divulgar esses resultados nas SREs para que elaborem planos/metas entre as áreas de conhecimento para que o $\mathrm{R}^{2}$ possa vir a diminuir.

\section{DEVELOPMENT OF THE CORRELATIONS OF THE NATIONAL HIGH SCHOOL EXAMINATION GRADES VIA TRACK ANALYSIS IN THE REGION OF CAPARAÓ}

\begin{abstract}
The National High School Examination (ENEM) contributes to the Federal Government with the definition of public educational policies, such as certification for those who did not finish high school. The objective of this work was to construct the tracking diagram that indicates
\end{abstract}


the relation of cause and effect among the knowledge areas evaluated by ENEM-2014 in the Caparaó region, with the mathematics as the basic variable. In the methodology, the tracking coefficient was used to visualize the direct and indirect effects in mathematics through other areas of knowledge assisting the visualization of cause and effect. The information was obtained on the INEP website in ENEM micro-data of that year, obtaining the average vectors by area evaluated from the state schools of Caparaó via school codes and all the information was handled on Genes software. In a quantitative of 1999 students who enrolled, 221 are NA scores (Not Available) in at least one of the areas assessed that were not considered in this study. The residual effect of the model was 0.460 and the $\mathrm{R}^{2}=0.790$, and it was observed that the variables Natural Science and Human Sciences showed direct and positive effects of 0.421 and 0.509 respectively; in Mathematics and Writing, 0.074, and Language Codes, 0.045, with approximately zero direct effects. It was observed that the indirect effects for all the other areas via writing were negative (null).

Keywords: Tracking diagram. Basic variable. ENEM micro-data.

\section{REFERÊNCIAS}

BRASIL. Ministério da Educação. Enem 2015: a segunda maior prova de acesso ao ensino superior do mundo. Brasília, 2015. Disponível em: < http://portal.mec.gov.br/ultimasnoticias/418-enem-946573306/31151-a-segunda-maior-prova-de-acesso-ao-ensino-superiordo-mundo>. Acesso em: 22 nov. 2017.

BRASIL. Ministério da Educação. Instituto Nacional de Estudos e Pesquisas Educacionais Anísio Teixeira. Exame Nacional do Ensino Médio (Enem). Brasília, 2005.

CARVALHO, C. G. P et al. Correlações e análise de trilha em linhagens de soja semeadas em diferentes épocas. Pesquisa Agropecuária Brasileira, v. 37, p.311-320, 2002.

COIMBRA, J. L. M. et al. Consequências da multicolinearidade sobre a análise de trilha em canola. Ciência Rural, v. 35, p. 347-352, 2005.

CRUZ, C. D.; CARNEIRO, P. C. S. Modelos biométricos aplicados ao melhoramento genético. Viçosa: UFV, 2003.

INSTITUTO CHICO MENDES DE CONSERVAÇÃO DA BIODIVERSIDADE. Parque Nacional do Caparaó. Alto Caparaó, [20--?]. Disponível em: <http://www.icmbio.gov.br /parnacaparao/4-parque-nacional-do-caparao>. Acesso em: 22 mar. 2017.

LI, C. C. The concept of path coefficient and its impact on population genetics. Biometrics, v. 12, p. 190-210, 1956.

MARCHEZAN, E. et al. Análise de coeficiente de trilha para os componentes de produção em arroz. Ciência Rural, v. 35, p. 1027- 1033, 2005. 
PAIVA, J. R. de.; ROSSETTI, A. G.; GONÇALVES, P. Uso de coeficiente de caminhamento no melhoramento de seringueira. Pesquisa Agropecuária Brasileira, v. 17, n. 3, p. 433-440, 1982.

SANTOS, R. C. dos; CARVALHO, L. P. de; SANTOS, V. F. dos. Análise de coeficiente de trilha para os componentes de produção em amendoim. Ciência e Agrotecnologia, v. 24, p. 13-16, 2000.

SEVERINO, L.S. et al. Associações da produtividade com outras características agronômicas de café (Coffea arabica L. “Catimor”). Acta Scientiarum, v. 24, p. 1467-1471, 2002.

Recebido em: 30/08/2017

Aprovado em: 09/10/2017

Publicado em: 11/12/2017 